\title{
Three Wall Orbital Decompression for Graves' Ophthalmopathy via a Coronal Approach
}

\author{
B. LEATHERBARROW ${ }^{1}$, J. LENDRUM ${ }^{3}$, P. J. MAHAFFEY ${ }^{3}$, J. L. NOBLE ${ }^{1}$, \\ J. KWARTZ ${ }^{1}$, H. DAVIES ${ }^{2}$
}

Manchester

\begin{abstract}
Summary
Ten patients with dysthyroid eye disease who underwent a three wall orbital decompression procedure performed via a coronal approach were reviewed. The indications, results, complications and surgical techniques involved in this surgery are discussed. We believe that this approach offers a number of advantages over other techniques and has a role in the management of carefully selected patients with dysthyroid eye disease who have severe unilateral or bilateral proptosis, with or without dysthyroid optic neuropathy.
\end{abstract}

It is generally held that the cardinal indication for orbital decompression in the treatment of dysthyroid eye disease is dysthyroid optic neuropathy. In a recent study, however, it was shown that among members of the American Society of Ophthalmic Plastic and Reconstructive Surgery and of the Orbital Society, more than $60 \%$ of orbital decompressions were performed for mild to severe exophthalmos to correct corneal exposure or disfigurement, while only $39 \%$ of these procedures were performed to relieve visual loss in compressive optic neuropathy. ${ }^{1}$

The indications for orbital decompression have certainly broadened with greater experience and understanding of the surgical techniques available. In addition to the "cardinal' indication, dysthyroid optic neuropathy, decompressions may also be performed for prolonged orbital congestion and pain, orbital problems resistant to steroid treatment, orbital problems where there have been steroid complications, and severe corneal exposure that cannot be treated with lid lengthening surgery. ${ }^{2}$

Many surgeons would now add severe exophthalmos with significant cosmetic disfigurement resulting in psychological trauma to this list. ${ }^{3}$ Some surgeons include decompression as a preliminary to ocular muscle surgery when there are more than $25 \mathrm{~mm}$ of proptosis bilaterally, which would be further increased if ocular muscle recessions were carried out to improve the diplopia. ${ }^{+}$

The surgical approaches available for orbital decompressions are still evolving and the choice of operation depends not only on the indications for the procedure but also on the individual surgeon. It is apparent that the procedure may be performed by a variety of surgeons; ophthalmic surgeons, neurosurgeons, otolaryngologists, plastic surgeons, and faciomaxillary surgeons.

The surgical approach chosen should be

${ }^{1}$ B. Leatherbarrow, J. L. Noble, J. Kwartz, Manchester Royal Eye Hospital.

${ }^{2}$ H. Davies, Department of Orthoptics, Royal Eye Hospital, Manchester.

${ }^{3}$ J. Lendrum, P. J. Mahaffey, Department of Plastic Surgery, Withington Hospital, Manchester.

Correspondence to: B. Leatherbarrow, FRCSE, FCOphth, Ophthalmic Surgeon, Royal Eyc Hospital, Oxford Road, Manchester M13 9WH. 
Table I. Orbital decompressions

\begin{tabular}{lc}
\hline Operations & Patients $(n=10)$ \\
\hline Bilateral & 7 \\
Unilateral & 3 \\
\hline
\end{tabular}

suited to the particular indication for the procedure rather than the patient subjected to the surgeon's favourite approach. Over the course of recent years the concept has gradually evolved that the reduction in the degree of proptosis and restoration of best-corrected visual acuity are, to a degree, independent of each other. ${ }^{2}$

It has been shown that by being aware of the different possible surgical techniques and by using the various investigations available, the surgeon can develop an individual decompression plan for a particular patient that will provide optimum results with the minimum morbidity. ${ }^{2}$

Various types of surgical decompression have been performed over the years. Every wall of the orbit has been resected for the purposes of decompression, singly or in combination. ${ }^{8-11}$ Some types are suitable for the ophthalmologists alone to perform; others require a team approach, with the help of a neurosurgeon or otolaryngologist. Since Dollinger's first report of an orbital decompression for Graves' disease, ${ }^{13}$ the surgical approaches have consisted of the lateral orbitotomy approach, the intracranial approach, and the inferomedial approach (external ethmoidectomy or transantral operation). The most commonly used types of modern decompression are:

1. Lateral decompression.
2. Antral-ethmoidal decompression, either via the translid or fornix approach or the transantral approach. ${ }^{6,14,15}$

3. 'Three wall decompression' in which lateral wall decompression is added to antralethmoidal decompression.

4. Kennerdell-Maroon 'four-wall decompression' in which the lateral wall portion of the 3-wall technique is extended. ${ }^{12}$

We present our experience with a 3-wall decompression procedure performed via a bicoronal skin incision which we believe offers certain advantages over other approaches for the management of disfiguring unilateral or bilateral proptosis of Graves' disease where the indication for decompression is severe corneal exposure with or without dysthyroid optic neuropathy.

\section{Patients and Methods}

We reviewed ten patients with a clinical diagnosis of Graves' ophthalmopathy who underwent a 3-wall orbital decompression performed via a bicoronal skin incision. The operations took place between September 1980 and March 1988. The patients were selected from referrals by ophthalmologists to the Plastic Surgery Unit of Withington Hospital, South Manchester. All the operations were performed by a single surgeon (JL). Six patients were male, four female. The age range was 37-70 years, with a mean of 50.7 years (Table II). Seven patients underwent a bilateral orbital decompression, and three patients a unilateral decompression. A total of 17 orbits were decompressed (Table I).

The indications for decompression in this series are shown in Table II. Four patients underwent decompression to relieve dysthy-

Table II. Indications for decompression

\begin{tabular}{rccll}
\hline Patient & Age & Sex & Indications for Surgery & Operation \\
\hline 1 & 37 & $\mathrm{M}$ & Exposure keratopathy & Unilateral \\
2 & 43 & $\mathrm{M}$ & Optic neuropathy & Bilateral \\
3 & 58 & $\mathrm{M}$ & Optic neuropathy & Bilateral \\
4 & 61 & $\mathrm{~F}$ & Cosmesis & Unilateral \\
5 & 70 & $\mathrm{M}$ & Exposure keratopathy & Bilateral \\
6 & 44 & $\mathrm{~F}$ & Exposure keratopathy & \\
& & & Recurrent globe luxation & Bilateral \\
7 & 33 & $\mathrm{M}$ & Optic neuropathy & Bilateral \\
8 & 62 & $\mathrm{~F}$ & Exposure keratopathy & Bilateral \\
9 & 47 & $\mathrm{M}$ & Optic neuropathy & Bilateral \\
10 & 52 & $\mathrm{~F}$ & Exposure keratopathy & Unilateral \\
\hline
\end{tabular}




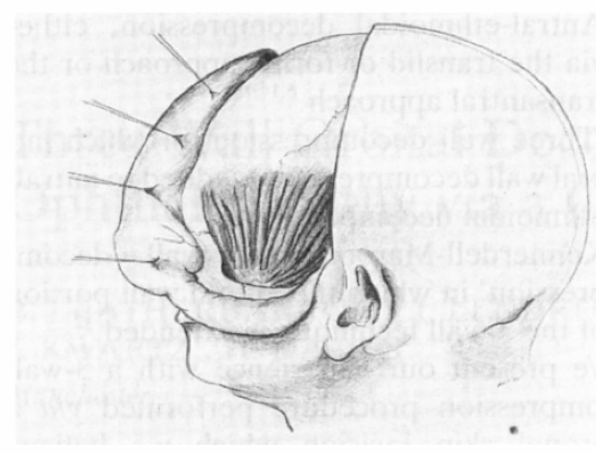

Fig. 1a.

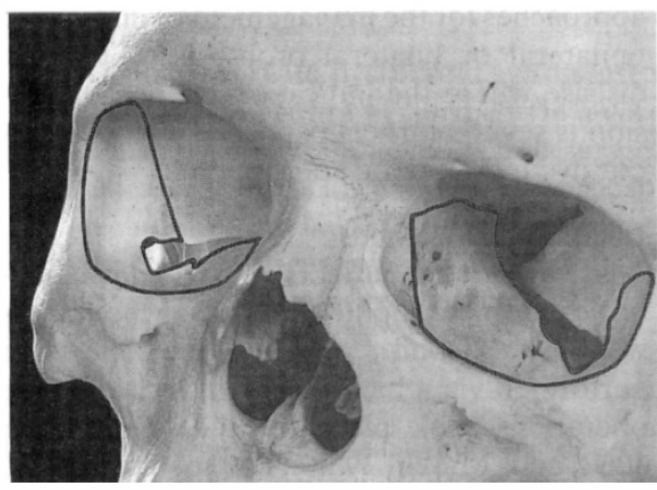

Fig. $1 b$.

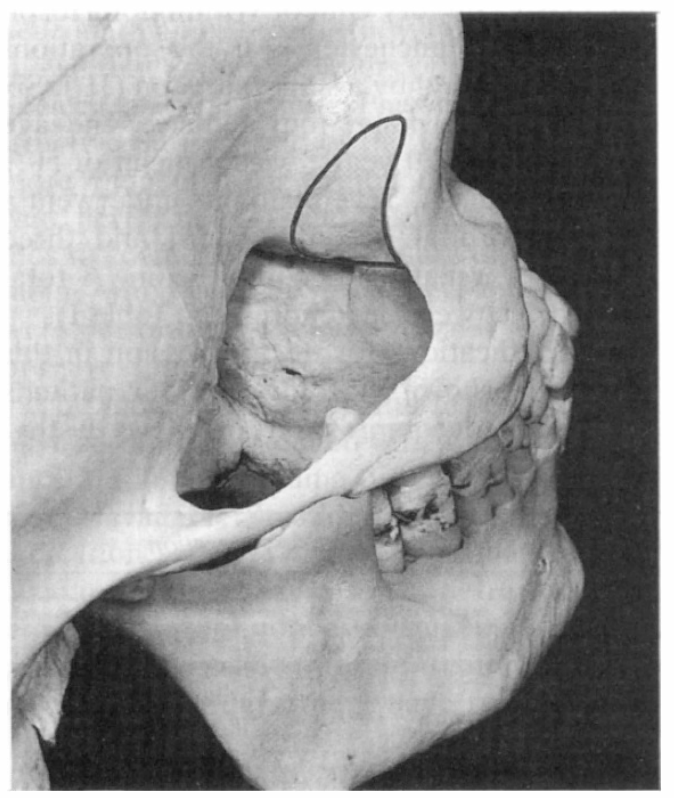

Fig. 1c

Fig. 1. A bicoronal flap approach to the orbit. The area of bone removed from the medial and lateral orbital walls and from the floor of the orbit is illustrated. roid optic neuropathy unresponsive to high doses of systemic corticosteroids. Five patients had severe exposure keratopathy which, it was felt, could not be controlled with standard lid-lengthening procedures. One of these patients also suffered repeated episodes of globe luxation. In only one of the patients was the cosmetic defect so disfiguring that a decompression was considered justifiable.

Pre-operatively the patients had undergone a thorough ophthalmic evaluation by an ophthalmologist. All the patients were recalled post-operatively for a separate assessment of the surgical results by a single observer (BL). The interval from surgery to this assessment ranged from 9-108 months with a mean of 45 months. The role of the plastic surgeon in these cases was purely surgical. The pre-operative evaluation of each patient was as follows:

Hertel exophthalmometry

Orthoptic evaluation

Optic nerve function tests

Visual acuity

Colour vision

Visual fields

Pupil responses

Optic disc examination after pupillary dilatation

Visually evoked responses

Slit-lamp examination

Applanation tonometry in the primary position and in up-gaze

Computerised tomography

Clinical photography

Endocrinology consultation

Pre-operatively eight patients had undergone treatment for thyrotoxicosis. Five of these patients had received radio-iodine, two had undergone thyroid surgery and one was taking carbimazole. One patient was hypothyroid and taking thyroxine. One patient had no demonstrable abnormality of thyroid function nor any positive serum antibodies, and was diagnosed as having Ophthalmic Graves' disease. All patients at the time of surgery were euthyroid. Pre-operatively all patients had received systemic corticosteroids in varying doses depending on the indications for their use. Those patients who had dysthyroid optic neuropathy received doses in excess of $80 \mathrm{mg}$ per day while those with severe soft tis- 
Table III. Pre-and post-operative visual status in patients with optic neuropathy

\begin{tabular}{|c|c|c|c|c|c|}
\hline \multirow{2}{*}{\multicolumn{2}{|c|}{ Patient }} & \multirow{3}{*}{$\begin{array}{c}\begin{array}{c}\text { Best Corrected } \\
\text { Pre-op }\end{array} \\
6 / 12\end{array}$} & \multirow{3}{*}{$\begin{array}{c}\begin{array}{c}\text { Visual Acuity } \\
\text { Post-op }\end{array} \\
6 / 6\end{array}$} & \multicolumn{2}{|c|}{ Visual fields } \\
\hline & & & & Pre-op & Post-op \\
\hline \multirow[t]{2}{*}{2} & OD & & & Central scotoma & Normal \\
\hline & OS & $6 / 12$ & $6 / 6$ & Central scotoma & Normal \\
\hline \multirow[t]{2}{*}{3} & OD & $6 / 18$ & $6 / 18$ & Central scotoma & Unchanged* \\
\hline & OS & $6 / 18$ & $6 / 12$ & Central scotoma & Unchanged* \\
\hline \multirow[t]{2}{*}{7} & OD & $6 / 6$ & $6 / 6$ & Normal & Normal \\
\hline & OS & $6 / 9$ & $6 / 6$ & Central scotoma & Normal \\
\hline \multirow[t]{2}{*}{9} & OD & $6 / 6$ & $6 / 6$ & Normal & Normal \\
\hline & OS & $6 / 9$ & $6 / 9$ & Central scotoma & Unchanged* \\
\hline
\end{tabular}

${ }^{*}$ Required radiotherapy post-operatively

sue signs and symptoms received doses no greater than $40 \mathrm{mg}$ per day. Systemic corticosteroids were used as a temporising measure only in these patients prior to definitive surgical management. They were used for a period of two to six weeks pre-operatively.

\section{Surgical Approach}

In the coronal approach, ${ }^{7}$ after shaving a strip of hair, a skin-muscle incision is made through the scalp just behind the hair-line from a point $1 \mathrm{~cm}$ anterior to each tragus. The subgaleal flap is turned down to the superior and lateral orbital margins. The dissection is then continued in a subperiosteal plane. The supraorbital nerves are identified and preserved where possible. The periorbita is reflected posteriorly from each wall of the orbit. The temporalis muscle is partially freed from its attachment, and the lateral wall of the orbit is removed anteriorly. The lateral orbital rim is left intact. The floor of the orbit is removed laterally, then medially sparing the infraorbital nerve. The medial wall is removed as far posteriorly as the body of the sphenoid and as far superiorly as the fronto-ethmoidal suture. The area of bone removed is illustrated in Figure 1. A series of longitudinal incisions are now made in the periorbita in a posteroanterior direction in all four quadrants of the orbit. Excess orbital fat can be clamped, cauterised and carefully excised if required to achieve additional decompression. Drains are positioned in the infratemporal fossae. The bicoronal flap is repositioned and sutured with a continuous locking suture.

The same subgaleal flap is created for both the unilateral and bilateral decompressions. The average operating time for a bilateral decompression is two hours. It is now advocated that this procedure is performed by a plastic surgeon in conjunction with an ophthalmic surgeon.

\section{Results}

\section{Visual function}

Four of the patients, patients 2, 3, 7 and 9 had dysthyroid optic neuropathy with diminished visual acuity, abnormal colour vision, central scotomata, and increased latencies on visually evoked responses preoperatively. The diminution in visual function had been gradual over a period of weeks. Their pre- and postoperative visual status is summarised in Table III. The visual dysfunction in these patients failed to respond satisfactorily to systemic corticosteroids prior to surgery. Following surgery patients 2 and 7 had a dramatic improvement in visual function, with recovery to normal visual function over a period of days. Patients 3 and 9, however, failed to recover visual function following surgery. These patients were recommenced on high dose systemic steroids postoperatively and were subsequently subjected to fractionated orbital radiotherapy with full recovery of visual function over a period of eight weeks.

Patient 9 was subjected to postoperative computerised tomography. This showed that the medial walls of the orbits had not been decompressed to the optic nerves (Figs. 2, 3). The surgeon had failed to recognise the importance of an adequate posterior extent to the medial wall resection in compressive optic neuropathy despite having an excellent view of this area. It is presumed that this was also the reason for surgical failure in the case of patient 3 although this was not proved as the 


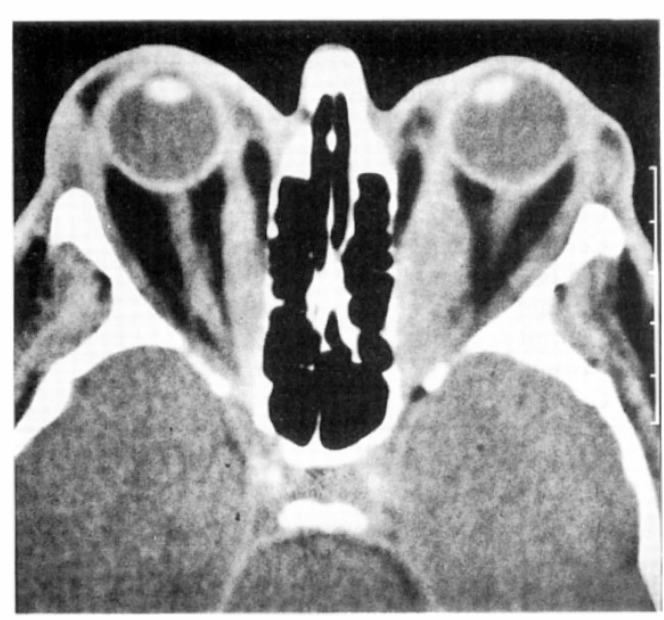

Fig. 2. Pre-operative axial CT scan of patient 9 showing enlarged extraocular muscles.

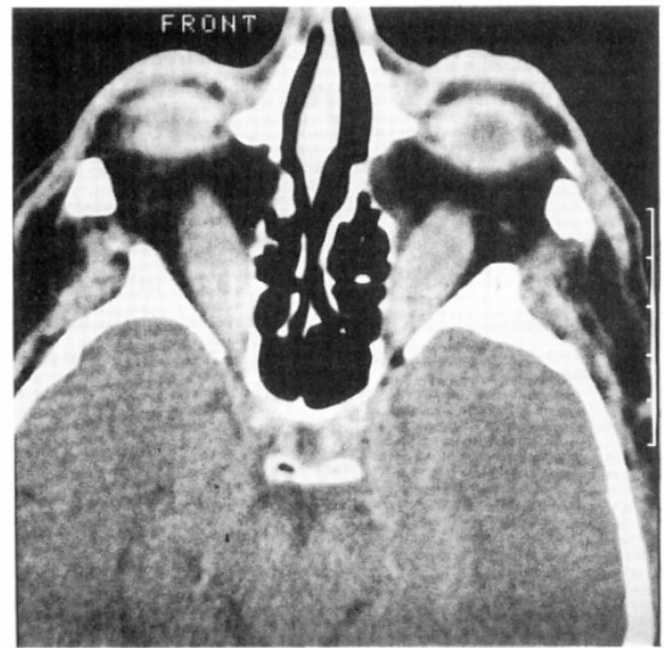

Fig. 3 Post-operative axial CT scan of patient 9 showing decompression of the lateral orbital walls but showing an inadequate decompression of the medial orbital walls.

patient did not undergo postoperative computerised tomography. None of these patients has so far developed any recurrence of optic neuropathy.

\section{Proptosis}

The average reduction in the degree of proptosis following surgery was $7.5 \mathrm{~mm}$ with a range of $2-12 \mathrm{~mm}$. THe readings for individual orbits are shown in Table IV.

Patient 8 achieved only a $2 \mathrm{~mm}$ reduction in the degree of proptosis of the left globe. As a consequence the left cornea still had exposure keratopathy postoperatively. She is awaiting lid lengthening procedures. In all other cases the reduction in the degree of proptosis was satisfactory. A typical case is illustrated in Figure 4.

Three of the remaining patients are also awaiting corrective lid surgery for upper and lower lid retraction.

\section{Strabismus}

Table $\mathrm{V}$ summarises the outcome of the 10 patients following orbital decompression surgery. Patient 5 was a high myope with gross myopic retinal degeneration, and patient 9 had a longstanding esotropia making accurate orthoptic assessments in these patients extremely difficult.

Fells reported 11 out of 14 patients, who underwent orbital decompression, to have a change in their ocular motility and many required extraocular muscle surgery to restore useful binocular single vision. ${ }^{+}$Our series substantiates this high incidence of postoperative ocular motility disturbance; eight out of our series of 10 patients suffered a significant reduction in their ocular motility and six a consequent reduction in their field of binocular fixation when present preoperatively. Of those patients without binocular single vision preoperatively, patient 10 reported

Table IV Exophthalmometer readings $\mathrm{mm}$

\begin{tabular}{|c|c|c|c|}
\hline \multicolumn{2}{|c|}{ Patient } & \multirow{2}{*}{$\begin{array}{c}\text { Pre-op } \\
-\end{array}$} & \multirow{2}{*}{$\begin{array}{c}\text { Post-op } \\
-\end{array}$} \\
\hline 1 & OD & & \\
\hline & OS & 26 & 18 \\
\hline \multirow[t]{2}{*}{2} & OD & 27 & 18 \\
\hline & OS & 26 & 18 \\
\hline \multirow[t]{2}{*}{3} & OD & 28 & 23 \\
\hline & OS & 28 & 22 \\
\hline \multirow[t]{2}{*}{4} & OD & - & - \\
\hline & OS & 25 & 22 \\
\hline \multirow[t]{2}{*}{5} & OD & 27 & 19 \\
\hline & OS & 26 & 18 \\
\hline \multirow[t]{2}{*}{6} & OD & 27 & 18 \\
\hline & OS & 28 & 18 \\
\hline \multirow[t]{2}{*}{7} & OD & 25 & 18 \\
\hline & OS & 25 & 17 \\
\hline \multirow[t]{2}{*}{8} & OD & 27 & 22 \\
\hline & OS & 24 & 22 \\
\hline \multirow[t]{2}{*}{9} & OD & 26 & 15 \\
\hline & OS & 26 & 14 \\
\hline \multirow[t]{2}{*}{10} & OD & - & - \\
\hline & OS & 28 & 19 \\
\hline
\end{tabular}




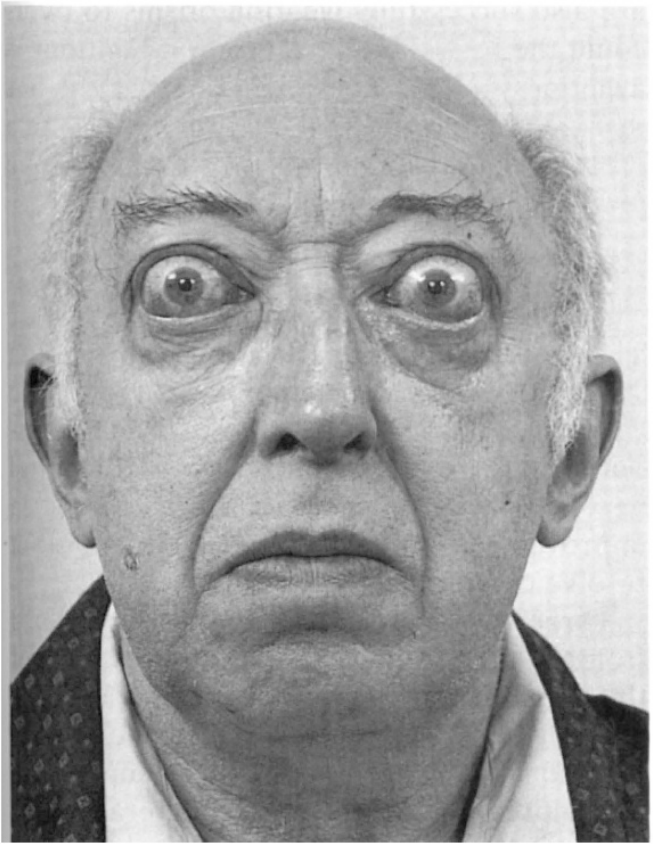

Fig 4a.

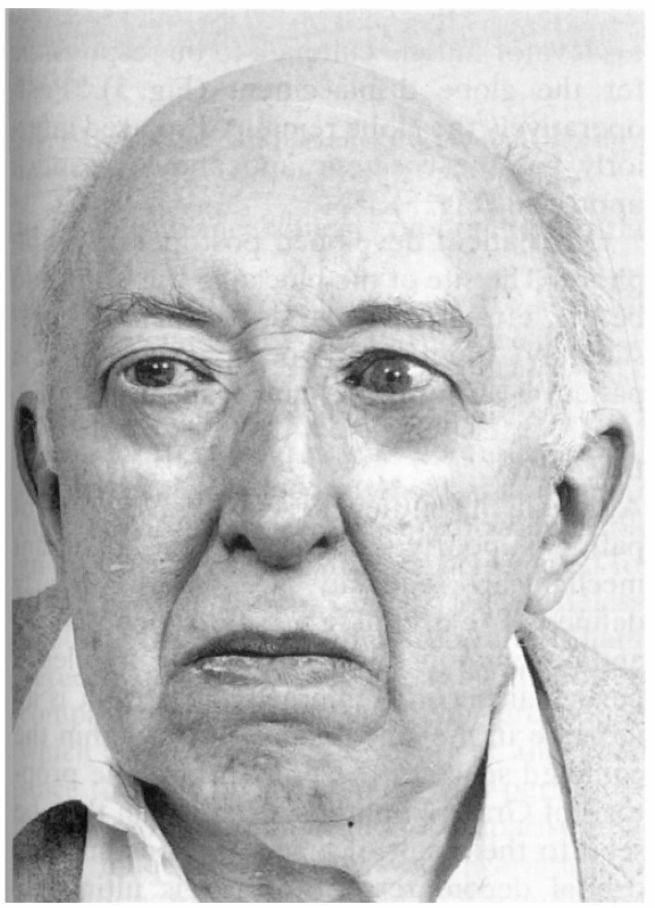

Fig. 4c.

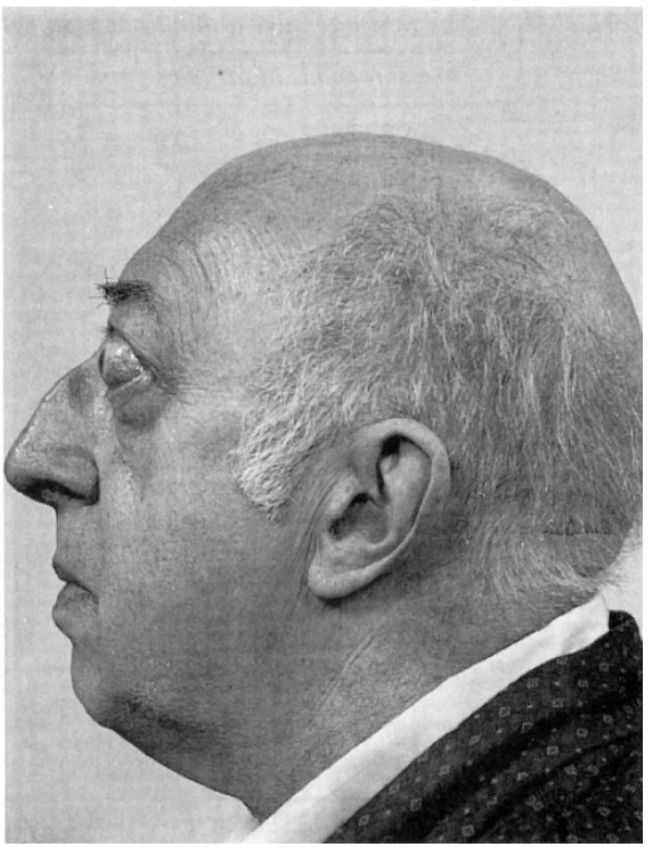

Fig 4 b.

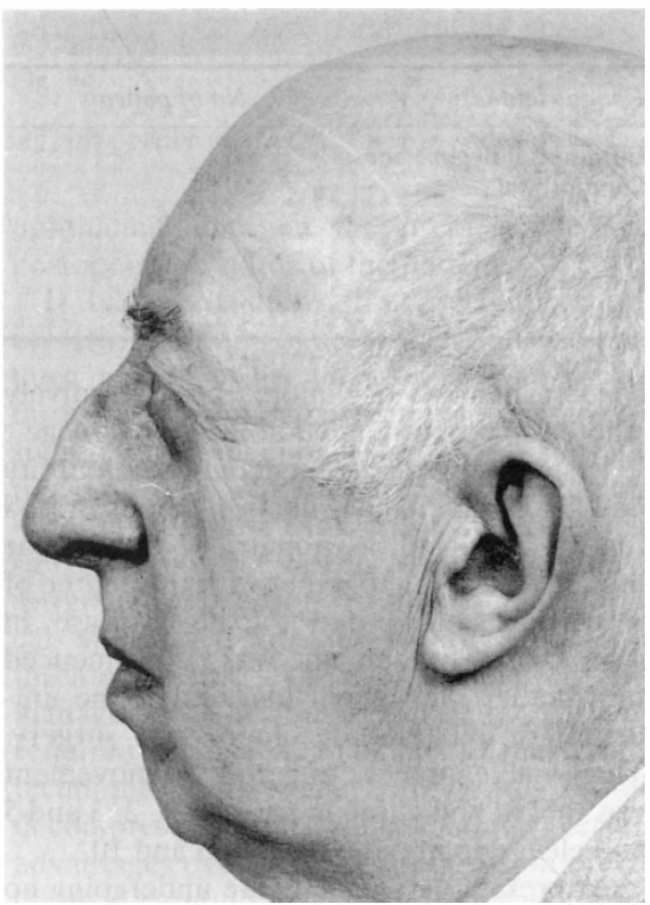

Fig. 4d.

Fig.4. Pre-and post-operative photographs of patient 5 . 
Table V Pre-and post-operative orthoptic assessment

\begin{tabular}{|c|c|c|}
\hline \multirow[b]{2}{*}{ Patient } & \multicolumn{2}{|c|}{ Measurements in primary gaze } \\
\hline & Pre-op & Post-op \\
\hline \multirow{2}{*}{$\begin{array}{ll}1 & \mathrm{~N} \\
& \mathrm{D}\end{array}$} & Ortho & $.4 \mathrm{ET}$ \\
\hline & Ortho & $8 \mathrm{ET}$ \\
\hline & Ortho & $6 \mathrm{ET}$ \\
\hline $\mathrm{D}$ & Ortho & 16 ET 2 RHT \\
\hline \multirow{2}{*}{$3 \mathrm{I}$} & Ortho & Ortho \\
\hline & Ortho & Ortho \\
\hline 4 & $25 \mathrm{RHT}$ & 9 RHT \\
\hline $\mathrm{D}$ & $25 \mathrm{RHT}$ & 9 RHT \\
\hline 5. & NA & NA \\
\hline$\cdot \mathrm{D}$ & NA & NA \\
\hline 6 & Ortho & $20 \mathrm{ET}$ \\
\hline $\mathrm{D}$ & Ortho & $20 \mathrm{ET}$ \\
\hline \multirow{2}{*}{$\begin{array}{ll}7 & 1 \\
& \end{array}$} & Ortho & Ortho \\
\hline & Ortho & Ortho \\
\hline 8 & Ortho & Ortho \\
\hline $\mathrm{D}$ & Ortho & Ortho \\
\hline \multirow{2}{*}{9} & 35 ET 10 RHT & 45 ET 10 RHT \\
\hline & 30 ET 8 RHT & 35 ET 8 RHT \\
\hline \multirow{2}{*}{10} & 25 XT 20 RHT & 45 XT $20 \mathrm{RHT}$ \\
\hline & 40 XT 25 RHT & 45 XT 25 RHT \\
\hline
\end{tabular}

Key: Muscle balance measured in prism dioptres; Ortho = orthotropic;

$\mathrm{ET}=$ esotropia;

$\mathrm{XT}=$ exotropia $; \mathrm{RHT}=$ right hypertropia $; \mathrm{NA}=$ not available.

Table VI Complications after orbital decompression

\begin{tabular}{lc}
\hline Complications & No of patients \\
\hline Infraorbital hypoaesthesia & 7 \\
Supraorbital & \\
hypoaesthesia & 6 \\
Epiphora & 1 \\
Frontalis palsy & 3 \\
Ptosis & 1 \\
\hline
\end{tabular}

worse symptoms of diplopia postoperatively whereas patients 4 and 9 noticed no change.

Postoperative assessment of ocular motility and fields of uniocular fixation demonstrated that, as expected, asymmetry of extraocular muscle restriction together with the degree of restriction contributed to the increase in symptoms. The outcome was not influenced by whether the patient had undergone unilateral or bilateral decompression surgery. The notable increase of restricted movement was that of abduction in patients 1,2, 3 and 5 and elevation in patients $3,6,8$ and 10 .

At present five patients are undergoing no active treatment; one patient is wearing a permanent prism successfully; two patients have undergone extraocular muscle surgery and are also successfully wearing prisms to overcome their residual deviation; one patient is awaiting surgery. The remaining patient has declined extraocular muscle surgery despite a gross deviation and debilitating diplopia. She prefers to wear a monocular occluder.

\section{Complications}

There were no intraoperative complications. The postoperative complications are listed in Table VI. The most common postoperative complication was hypoaesthesia in the distribution of the supraorbital or infraorbital nerves. Although the degree of hypoaesthesia improved with time, in only one patient did it resolve completely.

Three patients were left with a unilateral frontalis palsy due to inadvertent division of the superior zygomatic branch of the facial nerve. This complication is avoidable.

Patient 1, who underwent à unilateral decompression, developed a unilateral partial ptosis postoperatively. Preoperatively the left globe was displaced inferiorly and the upper lid was retracted (Fig. 5). The coronal CT scan shows a markedly enlarged superior rectus/levator muscle complex to be responsible for the globe displacement (Fig. 5). Postoperatively the globe remains displaced inferiorly but the cosmetic appearance is much improved (Fig. 5).

One patient developed postoperative epiphora. The site of the blockage was shown to be the left nasolacrimal duct which was presumably traumatised peroperatively. The patient is awaiting lacrimal drainage surgery.

\section{Discussion}

Although the pathogenesis of Graves' orbitopathy is poorly understood, the resultant mechanical sequelae are more clearly defined. The orbital tissues become inflamed and oedematous. The extraocular muscles in particular become enlarged. The result is an increase in the soft tissue volume within the confined space of the bony orbit. The proptosis of Graves' ophthalmopathy can then be seen to the result of a spontaneous anterior orbital decompression, which is ultimately limited by the eyelids, the orbital septum, the rectus muscles and the optic nerve length. Dysthyroid optic neuropathy is now thought 


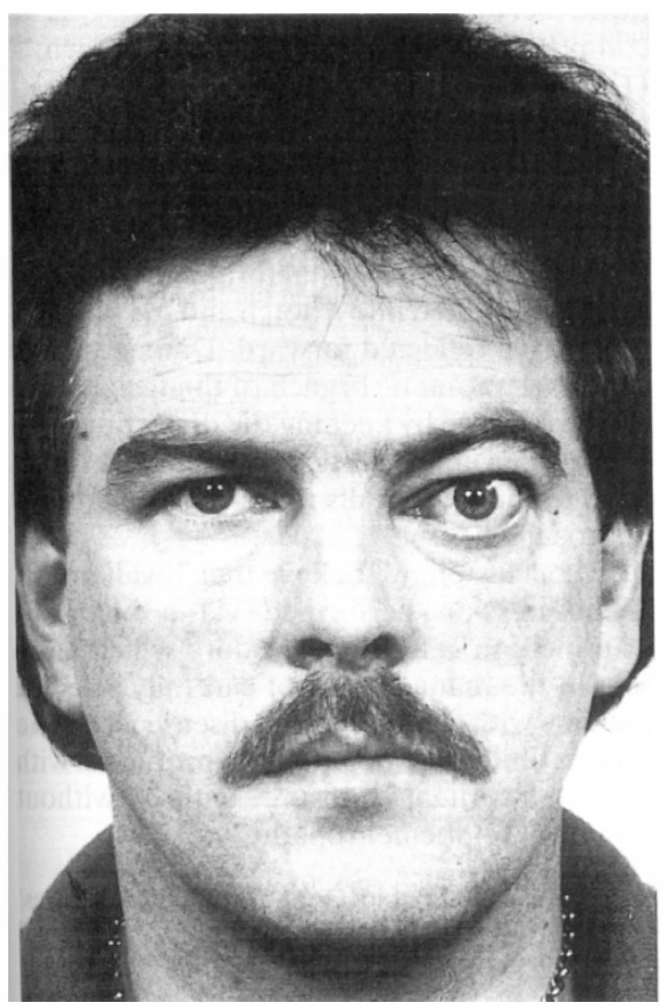

Fig. 5a.
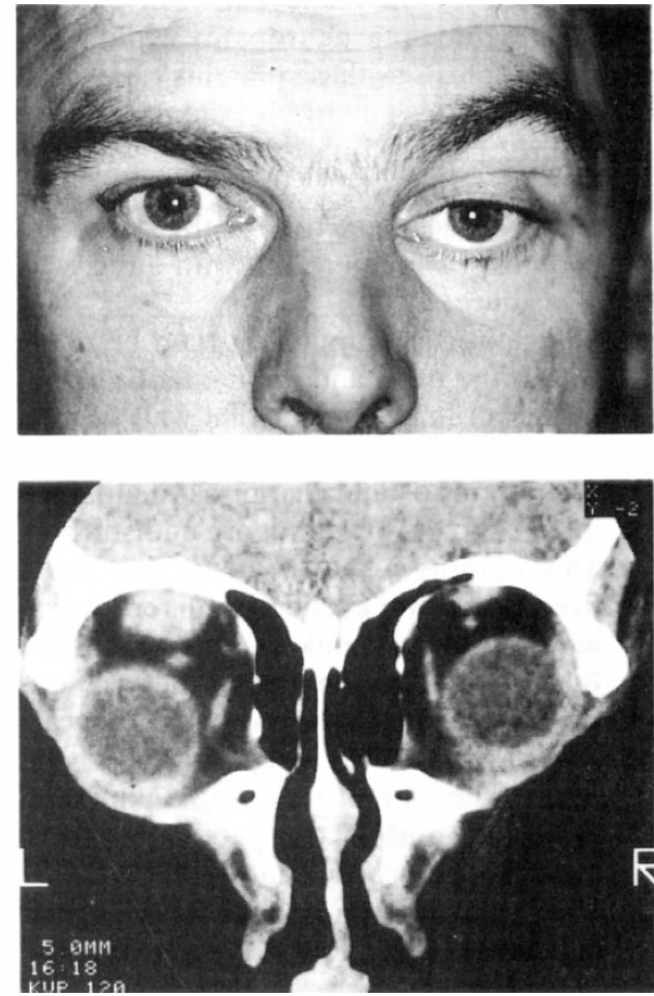

Fig. 5c.

Fig. 5. Pre-and post-operative photographs of patient l, and post-operative coronal CT scan of patient l showing an enlarged left levator/superior rectus complex.

to be due to mechanical compression at the orbital apex.

The underlying cause of dysthyroid eye disease remains obscure, and no specific treatment is available. Until such specific treatment is available, orbital decompression as a therapeutic measure will continue to be required by selected patients. A number of decompression procedures are now available and a suitable procedure can be selected for the individual patient's needs. Nevertheless. selecting the most suitable procedure is hampered by the great difficulty in making direct comparisons of the different procedures which have been described over the years since the first decompression was performed for this condition in $1911 .^{13}$ Comparison has been made difficult by wide variation in indications for surgery, even within individual series. This series is no exception in this respect. In addition, many reports are from non-ophthalmologists and lack adequate ophthalmic data on the preoperative and postoperative status of the patients.

It has been shown that decompressions involving ablation of more than one wall produce better results than single wall procedures, but 'undercorrection' remains a significant problem in cases where a substantial reduction in the degree of proptosis is required. In these cases a 3-wall decompression is required. We do not believe that a 4-wall decompression requiring a neurosurgical approach, with all its attendant lifethreatening risks, is ever justified in the management of these patients. All the required objectives can be met by much safer techniques. We believe that this 3-wall decompression procedure offers certa . advantages over other decompression procedures in carefully selected patients who have severe unilateral or bilateral proptosis with or without dysthyroid optic neuropathy. It is an extensive surgical procedure, however, and is 
not justified for the management of patients with dysthyroid optic neuropathy without significant proptosis as these patients can be satisfactorily managed by a simpler 2-wall procedure. The advantages of our 3-wall procedure are as follows:

(1) The average reduction in the degree of proptosis is greater than with any 2 -wall procedure.

(2) Safer direct manipulations can be made within the orbit and the posterior extent of the all important medial wall decompression can be directly visualised.

(3) The lateral orbital margin is maintained intact, and the lower lids are undisturbed. This permits a more satisfactory result from later lower eyelid margin repositioning procedures should these be required.

(4) In the female patient the cosmetic results are far superior as the postoperative scars are not visible. This is of particular advantage to the patient requiring a unilateral procedure and to the patient prone to hypertrophic scar formation. ${ }^{16}$

(5) The periorbita can be incised in all four quadrants. This allows a greater prolapse of orbital fat which can also be removed conveniently and safely for additional decompressive purposes. There is a theoretical advantage that incising the periorbita in all four quadrants may not significantly alter the ocular muscle balance, although this was not borne out in our series. ${ }^{4}$ Globe retrodisplacement depends not only on the configuration of the bony opening but also on the amount of periorbital opening and on the compliance of the orbital tissue. All other factors being equal, patients having more severe fibrosis and 'stiffness' of the orbit cannot be expected to obtain as much retrodisplacement as patients who do not. Our approach allows much greater opening of the periorbita to be obtained than can be achieved in 2-wall procedures or in other approaches to 3-wall decompression.

The procedure has few disadvantages over other described decompression operations. The operating time is longer and the postoperative inpatient course is more prolonged. The operative and post-operative morbidity is, however, no greater than that occurring in other decompressive procedures. ${ }^{1,5,15,16}$ Two complications are unique to this approach:

(1) Forehead anaesthesia.

(2) Frontalis palsy.

Both these complications are avoidable. The supraorbital nerve can be easily identified and reflected forward with the bicoronal flap. Where a true supraorbital foramen exists, this can be converted into a notch and the supraorbital nerve reflected forward. Damage to the superior zygomatic branch of the facial nerve can be avoided by keeping the dissection deep to the galea aponeurotica and then just superficial to the temporalis muscle as the latter is approached.

In conclusion, we believe that 3 -wall orbital decompression performed via a bicoronal skin incision is a safe procedure which has a role in the management of carefully selected patients with dysthyroid eye disease who have severe unilateral or bilateral proptosis with resultant corneal exposure, with or without dysthyroid optic neuropathy.

Key words: Dysthyroid Optic Neuropathy, Graves' Disease, Orbital Decompression, Thyroid Ophthalmopathy.

\section{References}

${ }^{1}$ McCord CD Jr: Current trends in orbital decompression. Ophthalmology 1985, 92: 21-33.

${ }^{2}$ Hurwitz JJ and Birt D: An individualized approach to orbital decompression in Graves. orbitopathy. Arch Ophthalmol 1985, 103: 660-5.

${ }^{3}$ Baylis HI, Call NB, Shibata CS: The transantral orbital decompression (Ogura technique) as performed by the ophthalmologist. Ophthalmology 1980, 87: 1005-12.

${ }^{4}$ Fells P: Orbital decompression for severe dysthyroid eye disease. $\mathrm{Br} J$ Ophthalmol 1987, 71: 107-11.

${ }^{5}$ Linberg JV and Anderson RL: Transorbital decompression: indications and results. Arch Ophthalmol 1981, 99: 113-19.

${ }^{6}$ Anderson RL and Linberg JV: Transorbital approach to decompression in Graves" disease. Arch Ophthalmol 1981, 99: 120-4.

${ }^{7}$ Trobe JD, Glaser JS, LaFlamme P: Dysthyroid optic neuropathy. Arch Ophthalmol 1978, 96: 1199-209.

${ }^{8}$ Hirsch $\mathrm{KO}$ and Urbanek J: Behandlung eines excessives Exophthalmos (Basedow) durch Entfernung von Orbitalfett von der Kieferhohle aus. Monatsschr Ohrenheilkd. Laryngorhinol 1930, 64: $212-13$.

${ }^{9}$ Naffziger HC: Progressive exophthalmos following thyroidectomy; its pathology and treatment. Ann Surg 1931, 94: 582-6.

${ }^{10}$ Sewall EC: Operative control of progressive exophthalmos. Arch Otolaryngol 1936, 24: 621-4. 
"Ogura JH and Walsh TE: The transantral orbital decompression operation for progressive exophthalmos. Laryngoscope 1962, 72: 1078-97.

${ }^{12}$ Kennerdell JS and Maroon JC: An orbital decompression for severe thyroid exophthalmos. Ophthalmology 1982, 89: 467-72.

${ }^{13}$ Dollinger J: Die druckenlastung der Augenghohle durch Entfernung der Ausseren Orbitalwand bei hochgradigem Exopthalmuz und konsekutiver Hornhauterkrankung. Dtsch Med Wochenschr 1911, 37: 1888-90.

${ }^{14}$ McCord CD Jr: Orbital decompression for Graves' disease; exposure through lateral canthal and inferior fornix incision. Ophthalmology 1981, 88: 533-41.

${ }^{15}$ Ogura JH and Lucente FE: Surgical results of orbital decompression for malignant exophthalmos. Laryngoscope 1974, 84: 637-44.

${ }^{16}$ Mourits M, Koornneef L, Wiersinga WM, Prummel MF, Berghout A, van der Gaag R: Orbital decompression for Graves' Ophthalmology by inferomedial plus lateral, and by coronal approach. Ophthalmology 1990, 97: 636-41.

${ }^{17}$ Stewart WB, Levin PS, Toth BA: Orbital surgery; the technique of coronal scalp flap approach to the lateral orbitotomy. Arch Ophthalmol 1988, 106: $1724-6$. 